\title{
Podcasting as Liminal Praxis: Aural Mediation, Sound Writing and Identity
}

\author{
By Dr Dario Llinares
}

You realise a world in which the principle mode of communication is oral is a very different kind of world in which the principle form of communication is written. It's something I hadn't thought about until I did a podcast - Malcolm Gladwell

The above quote from Malcolm Gladwell (Longform, 3 August 2016), about the writer's first venture into podcasting - a series entitled Revisionist History - encapsulates a philosophical interrogation and self-examination that emerges from working within the still relatively new sound medium. The question of what is the principle mode of communication in today's media saturated world, is itself a debateable one. However, I doubt whether sound would trump text or image in anyone's hierarchy of importance. Yet Gladwell is one of an increasing number of writers, artists, filmmakers, critics and academics, who have turned their hand to podcasting as an adjunct, subsidiary or development of their primary area of expertise. Such moves may be derived from the desire to accrue economic, cultural or social capital, by diversifying into a medium that is arguably going through a 'golden age' (Berry 2015, Ganesh 2016), but which retains an edgy, alternative aura. Yet, when listening to the experiences of podcasters discussing the form, a sense of self-reflection around the processes and effects of mediation, is often apparent. Gladwell, being a journalist and non-fiction writer is interested in the relationship, or disparity, between oral and written communication. He ruminates on how podcasting opens up questions concerning how the form of communication is inherent to the production and ontology of knowledge therein. Furthermore, Gladwell is not alone in suggesting that podcasting seems to engender a reflexive practice in the producer, inspiring interrogation of one's self-conception and agency as a mediated subject.

Engagement in the diverse of range practices required in the production of podcasting, and an attendant effect of critical (self)interrogation as a mediated subject, is a phenomenon that I have experienced in my own venture into podcasting. The Cinematologists Podcast stemmed from the fundamental pleasure of discussing cinema, with my colleague Dr Neil Fox, along with ruminating on various other interrelated subject: the rigid strictures of academic production and dissemination, the mill of research and publication, the possibilities and pitfalls of the internet as a space for debate, and transformational effect of digital age on all aspects of cinema. Both Neil and myself had also become avid podcast listeners, not just film related but in many different areas, sensing that some of the most articulate, insightful and relevant conversation was taking place in this independent and idiosyncratic audio space. In developing the format for The Cinematologists - recorded in a live venue, around a specific film screening, with audience debate the central component - we attempted to explore and utilise the characteristics of an audio medium to adhering to the sensibility of the cinema-going experience, and the enjoyment of discussing a film after you have watched it.

Becoming a podcaster has meant I have learned a range of technical skills - sound production and editing, online distribution, social media marketing and audio presentation - which, beyond their instrumental value, provoked questions around the relationship between languages of mediation and the ontology of knowledge. Furthermore, the experience of podcasting also fostered 
spirit of community, respectful and reasoned debate, and even a space and time for academic discourse that is arguably becoming more marginalised in the university itself. The amalgamation of creative audio experimentation with the fundamental spirit intellectual curiosity and the idealised aspects of the internet's communicative potential, I have found hugely satisfying. This experience I conceive of as a kind of positive destabilization; an exciting and potentially revelatory disruption of the boundaries that tie disciplines and fields of inquiry to specific forms of expression and institutional practice. In this sense, I have come to think of podcasting as a 'liminal praxis': a mediatory practice that emerges out of an idiosyncratic yet fluid set of technological, economic, creative, social and disciplinary conditions, and which, concomitantly, imbues a questioning of the logics and effect of the mediation itself.

Drawing upon the self-reflexive discourse of podcasters (including myself) who have come to this sound medium from other disciplines - using interviews on published podcasts and my own recorded interviews - this chapter is an exploration of mediated communication of knowledge and identity through podcasting. I begin by anchoring podcasting within the concept of liminal praxis, schematising the interrelationship between technological, industrial, socio-cultural and aesthetic parameters which has facilitated a unique, and perhaps contingent, creative context for podcasting to emerge. Subsequently, I explore the relationship between written and sound communication, arguing that the oral and aural mechanics of the podcast offers potential to disrupt the logocentric biases in knowledge creation and dissemination. This leads on to an analysis of the parameters of autonomy and self-articulation experienced by podcasters through their sonic practices of being and doing mediated subjectivity. I argue that podcasting thus offers freedoms from disciplinary regimes and traditions, and from sanctioned modes of communication and knowledge production. This leads to the counter-intuitive assertion the podcasting provides a mechanism by which producer/consumers use the medium to define and enact their own agency within the highly fractured subjectivity of the internet age.

\section{Sound Mediation Praxis in Context}

Despite the inception of podcasting in the mid-2000s there are still questions as to its definition and identity as a discreet media form (Bottomley 2015). The most obvious ambiguity derives from easily made, yet problematic, correlation with radio regarding infrastructure of production, forms of sound content creation, and practices of listening (See Berry 2006 and chapter 1 of this volume)

Understanding podcasting as discreet from radio initially lies in the technological and distributive shift from the broadcast signal to the digital dissemination of individual audio files situated on an internet host and sent out to podcast catcher software such as iTunes or PlayerFM'1 ${ }^{1}$ Yet, Nele Heise (2016:1) drawing on work of Markman and Sawyer (2014), highlights the complexity of defining podcasting beyond its 'technological features (RSS-based distribution and subscription, downloadable audio files), because it can be understood "as both a simple distribution channel for existing content and an

\footnotetext{
${ }^{1}$ This is further complicated by related forms and concepts of digital audio dissemination such as DAB, streaming radio and netcasting.
} 
emerging programming vehicle", as well as "a new or hybrid media form that is accessible to amateurs as well as to media professionals (2014: 21)"'. The medium is utilised as a secondary platform the technological specificity of which allows the transference of content produced through established media forms and institutions. Yet simultaneously, that technology has also forged new creative possibilities of production, distribution and exhibition which, in turn, has given rise independent cadre of producer/consumers who have forged a new sound media culture. The 'hybridity' mentioned above, echoed by Middleton's (2013) characterization as 'a flexible medium', reflects an ontology of podcasts and podcasting which sits at the nexus of production and consumption technologies, practices and identities. It is through the notion a liminal praxis that I an attempt to offer a conceptualization of being and doing of podcasting.

Praxis is a salient term (which has an in-depth philosophical history that is beyond the scope of this article) in that it suggests the realising of knowledge and truth through the experience of practice. As Cowley outlines, tracing back to Aristotle, praxis is a move to overcome the fissure between mind/body, theory/practice dualisms that created a fundamental hierarchy where: "any form of practical activity is seen as 'base', and is carried out by the 'average man', while sublime theoretical life becomes confined to the elite, resulting in a general depoliticization of the 'average' people as they concern themselves with practical activity and everyday needs" (2008). The echoes of this fissure between theory and practice still reverberate through the history and philosophy of Western thought, particularly acute in education. Indeed, Cowley discusses its deployment by Hegel, Marx, Nietzsche and Sartre as a productive dialectic that synthesises theory and practice. Praxis has also been adopted in pedagogic research with the work of Paulo Freire (1970) being particularly influential in advocating for the primacy of lived experience with knowledge formulated through reciprocal dialogue between equal subjects rather than top down hierarchy of teacher/student. The emergence of digital media technologies has of course had wide-ranging implications with regards to how knowledge is conceived, created and communicated forging new possibilities of synthesis between theory and practice. Podcasting specific technological structure, its essential interconnection with the transformative applications of the internet, have created new audio practices and experiences that can and should be read socio-culturally. But more than that it is its very liminality - it's ontology of inbetweenness - facilitates a praxis in which podcasters are challenging conventions of mediation.

At the centre of the correlation between podcasting's technological function and its mediatory effects is Apple's iTunes. The default home for capture and dissemination since Steve Jobs first announced podcast integration with iTunes 4.9 in $2005^{2}$, its ubiquity and dominance as podcasting's foundational architecture is undeniable. ${ }^{3}$ However, longstanding gripes with Apple's commitment to podcasting are manifold: lack of digital infrastructure development, uncertainty around download and subscription metrics, erroneous methods by which podcast charts are measured, and Apple's overarching reputation for clandestine decision-making, to name but a few. ${ }^{4}$ Yet the specific

\footnotetext{
${ }^{2}$ You can see this on Youtube: https://www.youtube.com/watch?v=IzH54FpWAP0

${ }^{3}$ Estimates as to the percentage of podcasts obtained through Apple's iTunes are difficult quantify accurately but this 2015 report by Clammr suggests that $82 \%$ of mobile listening happens on iOS devices and $78 \%$ of iOS listening occurs through Apple's podcast app: http://rainnews.com/report-apples-importance-in-podcast-delivery/

${ }^{4}$ Various (unnamed) luminaries in podcasting reportedly met with iTunes executive to air grievances (Herrman. The New York Times, May 7, 2016).
} 
parameters of the iTunes framework, which makes it free for anyone to upload their audio content, doesn't allow producers to charge, and has no embedded hierarchy to distinguish between institutional and independent production, has, perhaps accidentally, facilitated a unique environment in which specific, even unique, creative culture has emerged.

Podcasting as liminal praxis intuitively lends itself to being contextualised in terms of the Jenkins' (2006) theoretical lineage of convergence culture, transmedia storytelling and the dynamics between so-called 'old' and 'new' media. The notion of convergence is, as Matt Hills suggests, concerned with multi-platforming: 'where media texts and audiences perhaps start to move almost seamlessly across different platforms such as television, online on-demand radio, podcasts, usergenerated content, digital video, and so on' (Hills 2011: 107). Convergence culture certainly buttresses the assertion that podcasting is 'just another distribution channel' offering consumers access points to content that is increasingly produced with such mobility in mind. There are many examples of podcasts that are explicitly designed around such practice - such as Welcome to Nightvale or Blood Culture - however they are not by any means, the dominant mode of output. Convergence asserts a reduced importance of platform specificity instead privileging the homogenous notion of content, where audiences engage in what De Certeau (1984) calls nomadic media consumption. RSS syndication method has given the listener control and with the arrival of the iPod, followed by the cultural ubiquity of the smartphone, audiences possess even greater autonomy with regards to choice, time, location, length and frequency of engagement. For McElearney and Middleton:

podcasting can be thought of as time and location neutral due to the asynchronous nature of the downloaded media involved and the way it can be distributed to multiple devices, whether fixed, mobile, connected or stand-alone; hence the use of terms such as 'time shifting' (Donnelly and Berge 2006) and 'space shifting' (Meng 2005). (2013: 24)

Mobility in a temporal and spatial sense puts the onus on the listener, whose jurisdiction over the when, where and how of podcast engagement, on the one hand suggests a highly liberated, even democratised consumer experience, but on the hand, reflects the atomization of the audience in the digital age. The abundance and availability of content, increasingly niche sensibilities and a saturated media landscape, creates an intense battle for audiences who have limited attention yet almost unlimited choice (Webster 2014). A central preoccupation of producers, the who, when, where, why and how of the atomised audience, is often articulated as the problem of digital production. Journalist Anna Sale discussing her show Sex, Death and Money, highlights how podcasting amplifies the labour of choice:

\footnotetext{
I love podcasting because when I started this show the thing that gave me terror was, you're not gonna just run into my show. Every time someone listens to the show they are going to have to make the choice to press play so every episode has to be an argument in favour of them pressing play (The Ezra Klein Show: 9 May, 2017)
}

Sale's comments reiterate the assumption around podcasting's subordinate relationship to radio, in terms of the broadcast infrastructure distribution, economic viability and historical dominance. Yet her awareness of the choice that is afforded to the podcast listener, the very labour implicit in selecting and consuming from that limitless range of possibilities, she suggests, adds value to the content that is 
selected for consumption. In a choice economy, infrastructure, marketing and distribution are all important factors, as they always were, in getting a media product out there and noticed. But consumer-led demand means that for every podcast, or series, that wants to grow an audience, the interest and quality of the content (however you might define that) has to stand for itself.

The idiosyncrasies of iTunes, along with the extensive possibilities of listening and sharing offered by smartphone software applications, which have amplified fundamental listener mobility and autonomy (Morris and Patterson 2015), are the basis of further formal and cultural outcomes that have shaped podcasting as a form. Principal among these is a dilution of distinctions, or more accurately, a levelling of distribution accessibility, between what Millette (2011) distinguishes as 'independent' and 'institutional' podcasting. The democratization potential of digital media was one of the central utopian claims upon the arrival of the internet. As with other strands of digital creativity, podcasting's independent sector has undoubtedly grown due to the relative cheapness and ease of use regarding hardware and software for sound recording, editing and online housing. Millette, in her research on Montreal's independent podcast community argues the podcasting has a "subcultural logic" that demarcates it from the institutional and production structures of radio and argues that 'independent' rather than 'amateur' should be used because of the considerably "advanced communicational and technical expertise" demonstrated by practitioners (2011: 5). Liminal praxis is therefore intertwined with podcasters self-conception being independently able to control their mediation, in terms of podcasting production skills and the autonomy of content, but in a context in which offers a sense of status and even power.

The iTunes platform is again central in helping to create the sense that small producers can compete alongside major brands on, in not a totally level playing field, at least on a fairer footing. As podcaster and academic Lance Dann states, 'At the moment actually we do still have a delicious situation where you can have very established highly funded programming appearing and charting alongside stuff done from people's back rooms' (Interview May 5, 2017). For independent podcasters, this sense of anarchistic frontier in which the distribution possibilities present a demarcation from but equality with the mainstream, even if this is somewhat illusory, is one of the attractions of podcasting. Perhaps in this regard podcasting is not so far from blogging, Youtube, social media, and elements of internet facilitated creativity, which amalgamates production, distribution and exhibition, bypasses institutionally enforced censorship, and have perhaps even points towards the promise of an effective public sphere. However, from my own experience and talking to other podcasters, the specific combination of production, exhibition and distribution control, allied to the particular advantages and idiosyncrasies of audio to transmit content and a subjectivity, has forged a sense of cultural uniqueness.

The discourses imbued through independent podcasting thus often reflect a sense of earnestness, serious vocation, community and even high-brow idealism. For journalist Michelle Dean, writing in The New Republic, this attitude permeates not only production but is also indicative of the podcast audience:

Even though podcasts share no particular style and very few conventions, a sense of high purpose lingers around them. Podcast listening carries with it a faint aura of cultural snobbery, a 
notion that to cue up an episode is to do something highbrow and personally enriching, whether it's a history lecture broadcast from a university, or an amateur talk show recorded in someone's garage. (March 28, 2017)

Apple's lack of development of the podcasting infrastructure may be primarily technological, but crucially, it is also economic. iTunes remains to this day set up as a system without any direct facility for monetization. An independent podcasting ethos has therefore developed through individuals and organizations built out of a passion and love of creating audio content. Dean rightly goes onto suggest that the 'essence' of podcasting is 'esoteric' and 'specialized', a form perfectly suited to the niche individualism of the Internet age. The levels of obsessive detail and depth can push podcasting into the worst excesses of pretentiousness, self-indulgence and navel-gazing.

Clearly the very nature of 'independence' is itself contestable in terms of how it is understood and enacted by podcasters, and whether audiences demarcate their listening choice according to independent $\mathrm{v}$ mainstream is questionable. However, podcasting's shift into mainstream consciousness is partly caused by its adoption as a secondary platform; another avenue for diversifying commercial potential of already existing content. Perhaps, this sense that podcasting is just a 'channel' is the clearest demarcation between independent and institutional sensibilities. Psychologist, academic and early adopter of podcasting Dave Brodbeck is vociferous in his independent sensibility:

I am proudly independent about it. This is my hobby. I don't do this for money. A bunch of us, in fact, have a facebook group mostly we are Canadian and it's confined to people who are indie people who are not trying to make money...Bob Goyetche ${ }^{5}$ one day at conference called Podcasters Without Borders was asked about monetizing and he said: "it's like asking me how l'd monetize fishing, this is my hobby. This is fun for me (Interview April 27, 2017)

Despite this allusion to an anti-commercial purity, as with many other aspects of internet content production, independent podcasters are fervently looking for ways to monetise audio content either through advertising, membership, sponsorship and patronage. One cannot deny the relationship between 'independent' and 'institutional' podcasting is not as clear cut as 'purists' might claim or desire. Indeed, now that the medium is reaching higher levels of mainstream cross-over the parameters that create traditional media hierarchies are increasingly influential. Despite the freedom of creativity afforded by the relative cheapness and ease of use of recording and editing equipment, the potential global distribution platform the internet provides, and the dynamics of social media as a marketing tool, the power of corporate organization, production values and 'star' name recognition are becoming increasingly significant in the supposedly cult world of the podcast. If iTunes is supplanted (or reconfigured) as the default distribution platform for podcasting one can imagine that a more explicitly economic infrastructure could fundamentally change how we see the impact and role of podcasts in the media landscape.

\footnotetext{
${ }^{5}$ Bob Goyetche was a Canadian podcasting pioneer who "co-organized the grassroots Podcasters Across Borders conference, and an early podcasting network". [Internet] Accessed 05/05/17 http://www.cbc.ca/radio/spark/335-the-lonelygeneration-and-more-1.3853837/tribute-to-podcasting-pioneer-bob-goyetche-1.3857832
} 
The dynamics of podcasting as liminal praxis, although perhaps not explicitly named as such, are explored in myriad ways throughout this book. In this chapter I want to move on to discuss how the fundamental element of sound is central to how podcasters reconceive of the relationship between thought and communication. This may seem like a blaringly obviously statement however it is fascinating to listen to podcasters, who have come to the medium from using writing as their primary form of expression, ruminate in a philosophical way about how podcasting opened up new understandings around how the form of mediation absolutely shapes the meaning and effect of the content. Of course, it is possible to argue that most audio formats are in some way based on a structural blueprint laid down in the written word. Audio books and radio plays are the obvious example and many podcasts are scripted to a degree. Interestingly, we have reached a point of where certain podcasts are being turned into books: Marc Maron has recently released a book based on his seminal WFT podcast entitled Waiting for the Punch (2017), The Smartest Book in the World (2015) is based on comedian Greg Proops' irreverent podcast The Smartest Man in the World and the hugely successful Philosophy Bites podcast, produced by David Edmonds and Nigel Warburton is a selection transcripts of podcasted interviews with leading philosophers. This could be read simply as another avenue of monetization, as indicative of the podcasting's increasing cross-over into mainstream sensibility or, as I postulate now, as suggestive of a shifting interrelationship between sound and writing in the context of digital media communication.

\section{Sound Communication and the Conditionality of Meaning}

In his interview on Longform, Malcolm Gladwell ruminated his anxieties and the unforeseen outcomes of moving from the textual to the sound medium:

I also had all these misapprehensions in the beginning cos I thought that it was just writing articles and saying them because these episodes are scripted...I sort of realised halfway through the process that it's actually a different kind of storytelling. And that's when I got really excited because I feel like I had discovered this thing that I hadn't known which is that when you're dealing in sound there's all kinds of things you can't do but there's all kinds of things you can do... The kind of emotions you can evoke are so much more powerful... I'm limited as a writer as I'm not good at eliciting strong emotional responses (Aug 3, 2016)

Gladwell's allusions to the storytelling distinctions between written and oral communication are a discovery that transmedia practitioners, or those working specifically with sound, know well. Yet his realization concerning the effect of an aural 'materialization' of the written word goes further, provoking the question of how the form of communication actually shapes meaning. Gladwell points out that even though his podcast is scripted - which of course implies the root of knowledge production as textual - articulation through sound evokes an emotionality that would not be produced if one was simply reading the words on a page. Implicit in Gladwell's comment is the effect that sound has in 
vivificating his own brand of non-fiction writing, which is heavily reliant on scientific research and statistical analysis, and arguably aspires to objective truth.

One might suggest that through podcasting Gladwell is encountering the contours of an ancient question with the regards to language communication and the relationship between speech (oral) and writing (textual). Plato's critique of writing, or more specifically the use of written text as a basis for transfer knowledge and the process of learning, is implicit in its 'stasis': its deadness or stillness. As John H. Fritz points out the Socratic contention is that writing cannot stand in for the activation of memory, or the rhetorical articulation of argument, that is produced by orated knowledge. Furthermore, the stasis of the written text precludes the possibility of functional challenging (as praxis) and thus its applicability to impart knowledge depends on the interpretation of the reader: 'written discourse is merely an image of the spoken discourse of the one knows and who writes in the soul of the learner' (2015: 173). Of course, one cannot escape the irony that our access to the Socratic dialogues is through the written record and it is even paradoxical to revisit considering the ubiquity of textual knowledge structures of Western modernity.

Derrida's controversial stake in the dichotomy between oral and written discourse asserts that language is an 'abstract possibility', a phenomenon of cognitive processes that subsequently finds outlet through the communication tools we learn (1976). His concept of archi-writing reflects the abstract notion that language is a present absence, suggesting that the fixity of the written form is a priori implicated within language's ontology, and thus writing is a kind of implicit blueprint that is the foundation of communication. Western modernity, even if it acknowledges the oral knowledge traditions, has, through the formalised structures of textual recording and dissemination, come to be fundamentally defined as the architectural underpinning of thought. Furthermore, the primacy of rationality is anchored to the doctrine of modern philosophy and science by the written text as a kind of evidentiary guarantor. Think of how much we take for granted as fact that which is written down, and the inherent suspicion attributed to hearsay. Yet Derrida's conceptions could be contrasted with Walter Ong's work on the relationship between orality and literacy, based on research into the thought and history of primary oral societies. He suggests that Western culture's focus on textual formation of language "have clamoured for attention so peremptorily that oral creations have tended to be regarded generally as variants of written productions or, if not this, as beneath serious scholarly attention" yet "written texts all have to be related somehow, directly or indirectly, to the world of sound, the natural habitat of language, to yield their meanings' (Ong 2002: 8).

In Gladwell's assertion above the effect of textual words materialised in sound is implicit in his use of the word emotion. 'The kinds of emotions you can evoke are so much more powerful' he states. The emotional effects of the spoken word are perhaps ubiquitously assumed to the point of being taken for granted, yet a specific philosophy of sound is relatively niche disciplinary area drawing upon epistemological and phenomenological theorizations of sound and its implications in specific contexts. Debates around intellectual versus emotional responses to music are a key focus (Gabrielsson 2001; Meyer 2008) and Augoyard and Torgue postulating the notion of the impact of sound akin to a 'sonic effect' in which 'sound has always been a privileged tool to "create an effect," to astonish (étonner, in its etymological sense). Sound undeniably has an immediate emotional power that has been used by 
everyday culture' (2005: 11). In terms of articulating written text, one cannot deny the role of the voice, as the essential instrument for both nuancing meaning and conveying emotional profundity. The resonance of speech operates both in dramatising of a story - injecting a sense of emotional texture to a narrative whether fictional or non-fictional - and as the vital component of public discourse, debate and argument. 'As many radio and audio producers who work regularly with voices as material object know, words alone do not do this; the voice - with all its tones, pauses, pitch changes, tremors, and stutters - can be highly revealing. A voice can be caught off guard no matter how well trained; inauthenticity detected; artifice and fabrication unmasked' (Madsen and Potts 2010: 48-49).

It is significant that a non-fiction writer like Gladwell puts so much emphasis onto storytelling and emotion as one of key advantages of podcasting and knowledge dissemination through sound. In many ways, disciplinary structures and practices of Western philosophy have side-lined or even sought to purge troublesome and messy emotion (Williams 1998). Textual writing, including literary fiction, poetry and other forms that are wrought with emotional evocation, are still bounded by their material presence or fixity. This is something picked up on in another interview with Malcolm Gladwell, this time on The Ezra Klein Show. Comparing the intellectual space of the podcast to that of the academic conference, he suggests they both serve as a forum for testing out ideas in condensed presentational format:

There is a reason why there is so much emphasis in academia on person to person oral presentation of arguments, data, what have you, because when it is presented in oral form it's so much easier to honour the conditionality of the work [my emphasis], to argue with it, to fix, to backtrack, to amend, to do all those things. The minute that it's on paper it has a kind of permanence and authority that maybe it doesn't deserve. (The Ezra Klien Show Aug 23, 2016)

This notion of honouring the conditionality of the work implicit within oral communication, is central to the rules of engagement in the public sphere. The parallel between the conditions of the academic conference, which is meant to foster a fluid and pliable sense of knowledge transfer, and the podcast is an apposite one. Indeed, echoing the work of Madsen and Potts (2010) Ezra Klein - Gladwell's interviewer - suggests a foundational connection between the 'spirit' of podcasting being in line with blogging:

I will say the thing about podcasting and I do not understand this exactly but one reason it is easier to talk about some of these issues in a way that feels similar to me to early blogging, people are a little more generous to the idea that you might be wrong and that might be OK, that might be part of searching on these issues (The Ezra Klein Show, Aug 23, 2016)

This correlation between the open, rule-breaking written form as a result of the early creative expression born of internet networked infrastructure is commented upon by Madsen and Potts: 'The broader social context of podcasting includes the culture of weblogging into which the new audio platform, and a rhizomatic "links" culture helping to extend the podcast through time and space' (2010: 36). For Klien this parallel contextual formal:

There is a subtle but very powerful incentive towards coherence imposed by most of the formats in which we write...one reason this format (podcasting) is nice is that you can be a 
little rambling, it doesn't have to be one point, people are open to you making just a bunch of points and then at the end just kind of moving on (The Ezra Klein Show, Aug 23, 2016)

The assertion here is that podcasting praxis offers a positive destabilization of the hierarchy between text and sound, reminding us of a more actively Socratic method of argument and learning, and perhaps even a framework of engagement, that is more productive in synthesizing ideas and positions than textual communication in era of the internet.

The appeal of the openness and flexibility of sound medium, particularly in terms of an implied conditionality of speech, could also, paradoxically, have become imbued with a greater sense of weight and veracity, in the context of the recent distrust of the written text online. It would be easy and churlish to appropriate the discourses du jour - post-truth and fake news - but podcasting's cultural significance has arisen concomitantly with digital superseding print, the attendant crisis in publishing, and collapse of the separation between professional and amateur writing. Indeed, podcasting arguably brings us to boundaries of what of Walter Ong defines as today's 'secondary orality of present-day high-technology culture, in which a new orality is sustained by telephone, radio, television, and other electronic devices that depend for their existence and functioning on writing and print' (2002: 11). Ong's notion of secondary orality was postulated well before the arrival of the internet and though I am not suggesting we are moving towards anything approaching a culture where orality becomes primary, podcasting praxis is a reminder and application of the communicative possibilities of language materialised through sound.

\section{The Podcasting Self}

Markman and Sawyer's $(2012 ; 2014)$ research represents an initial scholarly gambit into the motivations of independent podcasters, revealing that the development of technical skills, locating a community through reciprocal relationships with other podcasters, and receiving positive reinforcement from the audience, were all factors. There is a paucity of research into the motivation and selfidentification of podcasters which, even in the time since Markman and Sawyer's study, may have changed markedly considering the expanded cultural visibility of the medium (the aspiration to monetize audio content, I would hypothesize as more prevalent). In my own conversations with podcasters coming from different disciplines (and listening to podcast interviews) the specific move to identify oneself as a podcaster is infused with a range of purposes and motives, but if a fundamental discourse exists it pertains to desire to forge independent, autonomous control and self-determination to shape what might be termed the mediated self. For myself, creatively adopting the audio form as mean of expression was the fundamental parameter. In turn, learning the technical aspects of production, building an audience whose feedback gives a strong sense of recognition, and working directly and indirectly within a podcast community, were necessary layers of the process that shaped my sense working in the medium. However, and again with indicative of a liminal praxis facilitated through podcasting, the combination of these 'instrumental' elements have forged a unique circumstance that has reframed how I think of my role, practice and identity as an academic. Undoubtedly, other elements of digital culture feed into that (e.g. use of social media, the parameters of open access) but podcasting has been singularly important in forcing a reconceptualization how 
theory and practice, form and content, the self and work interrelate. Indeed, podcasting through its very liminality, particularly with regards to the fusing of material and digital ontologies - the centrality of physical presence, conversations with others, the use of the voice, all of which are captured, shared and listened to digitally - offers a profoundly valuable approach to mediating subjectivity.

In the internet era, the deployment of multiple definitions or categorizations of self, or even a refusal of them altogether, reflects the disseminated, fractured subjectivity we experience today. Looking at my own self-declared online biography, repeated across various platforms, I currently claim the titles of 'writer, podcaster and academic'. In my mind, these subjectivities are interrelated but I am certain that the order of them was a subconscious (perhaps even conscious, I can't quite remember) assertion of hierarchy. These are not just statements of fact, such self-definitions revolve around complex concerns about who you are, what you do, and how you want to be perceived as a social actor. Rachel Leventhal-Weiner, producer and host of Boy $v$ Girl: A podcast, has a website biography that reads, 'I balance the responsibilities of associated wife, parent, college professor turned policy analyst, storyteller, podcaster, sister, and friend with relative grace and poise (and lots of coffee)'. This proliferation of selves here, allied to a stylistic knowningness and self-deprecation, is almost a celebration of a complex multiplicity that crosses the boundaries of work, family, lifestyle, citizen and personality. Clearly how we define ourselves, whether it is a conscious biography like this, or the myriad forms of self-presentation we engage in daily, the determination of being is an inherent process of, increasing interrelated, online and offline labour.

When I interviewed Leventhal-Weiner we discussed how her sense of self fed in the development of her podcast:

\begin{abstract}
We started October 2015, back then I was a little nervous to call myself a sociologist and a writer on the podcast, but now that is who I am, that's the lens I bring to it. I was worried a little bit about putting those two things together and using that in the medium to share any kind of idea no matter how deep. (Interview, 5 May 2017)
\end{abstract}

Clearly in this statement Leventhal-Weiner foregrounds the sociologist and writer aspects of her identity as the primary drivers behind the podcast that she produces. Indeed, it is implied that her podcast is merely a secondary platform through which her primary vocations extended, explored and even combined. She even questions the viability of podcasting to explore the relationship between the two fields. But she adds to this:

\begin{abstract}
What's wild is that, as an academic, and I think some of this is as a woman, and I think some of it is that I came to the academic space at a non-traditional age, I didn't come straight through university like some of my colleagues did. I was dealing with a lot of imposter syndrome... and so for a while I felt like an imposter in every space I was in. Like, I'm not really a podcaster...but now I really identify with it and after learning at least the nuts and bolts, and I'm still always learning, I see it as a form that I can use in so many different ways. If I was ever to become a capital A academic again, or to have my toe in both worlds, that would be my medium. I almost wouldn't waste my time with journal publishing. (Interview, 5 May 2017)
\end{abstract}

Leventhal-Weiner fuses other elements of identity (academic, woman, imposter) in a narrative of selfdefinition, and then asserts that learning to podcast enabled these strands of identity and practice to coexist in a form of positive evolution. Overcoming 'imposter syndrome', by finding the confidence to 
inhabit the identity of an 'academic', and using the medium questioning tradition academic research dissemination, are achieved through praxis enabled by podcasting. The technical aspects of this are implied rather than explicit (learning the nuts and bolts), but the outcome is evocative of praxis in that active experience of podcasting is ingrained into a production of knowledge. Certainly, I recognize both these outcomes from my own experience of podcasting (indeed I address the question of academic podcasting in Knowing Sounds (2018) as a space where multiple aspects of the self are an inherent part of the praxis. As another interviewee, Dave Brodbeck put it, 'disparate parts of me get put together that wouldn't have been put together before'. (Interview April 27, 2017). One might argue that podcasters though the medium feel able to synthesize aspects of the self that may traditionally be kept isolated.

Another element of identity that Leventhal-Weiner alludes to above is gender, specifically reflecting on how one is judged and treated as a woman in an academic environment, the impact this can have on self-perception, and the positive effect of podcasting in negotiating those issues. Gender is also at the central of both the form and content of Sarah Williams' Tough Girl Podcast, which explicitly uses the medium to share experiences and stories of achievement from a female perspective:

\begin{abstract}
When I started going into local schools to talk about challenge and change, raising aspirations and having goals I became very aware that there weren't enough female role models out there and initially I was going to blog about it but then actually podcasting was just an incredible way to share these women's stories but also through the power of their voice and when these women are talking you can hear the passion in their voice, the drama, or when they went through challenging times and you can hear that emotion. I think it's an incredibly powerful medium (Interview 5 May 2017).
\end{abstract}

Williams reiterates a link between sound and emotion as fundamental to storytelling particularly with the articulation of female subjectivity as the driving force. Pointedly, she makes the distinction in terms of impact between blogging and podcasting with the power of the female voice the key parameter. It this sense it is the materiality and specificity of the female voice, articulating the stories of achievement, that imbue an emotional resonance and significance. Williams' advocacy of podcasting thus relates to a specific potential to for the medium represent women:

\footnotetext{
At the moment for me mainstream media just does not represent women you just don't get to hear their voices. So, you have so many women out there who are starting their own blogs, starting their own podcasts, starting their own YouTube channels and there is almost this groundswell and the fact that I can be part of it is amazing (Interview, 5 May 2017)
}

Williams highlights how she sees podcasting as an opportunity, again relating to the medium's perceived non-mainstream sensibility, to explore the issues and stories of women, specifically here with the intention of inspiring action in other fields. This throws up an interesting incongruity (worthy of further study) when considering Markman and Sawyer's assertion that podcast production is 'dominated by technologically savvy, educated, older, professional males' (2014: 30). Williams also suggests that podcasting should be understood part of a broader online community of practice, perhaps implicitly alluding to online or 'fourth wave' feminism (Munro 2013). 
An association between emotion response and sound, particularly the practice of listening over visual communication, is something that is alluded to by Lena Dunham. In discussing podcasting in relation to her (then) new show Women of the Hour she states:

There is something amazing about removing the visuals and this kind of beautiful experience of really listening, that is so, not to get too primal and deep but there is something really primal and human about listening. It has like attuned me in a new way. Listening to the cuts you send me, interviewing people, listening to the speech patterns, I feel like it's given almost like a new super sense. (Longform October 28, 2015)

Most obviously identified as creator of the TV show Girls, Dunham attests a new-found appreciation of the 'deep' experience of listening as actually having impact on her understanding of mediation though sound on a fundamental level. There is an interesting further question that emerges from this related to what impact the uptake in podcasting may have had on how audiences perceive listening in the digital context (perhaps in relation viewing/reading). Furthermore, there is an allusion here to the effect of the editing process itself; again, an element of the praxis of podcasting, in this case audio editing itself is asserted as enhancing Dunham's understand of the way 'speech patterns' influence communication. She defines this as becoming more 'attuned' which is a concise exemplification of how working in the podcast medium influences ones understanding of mediated subjectivity.

In listening to podcasters talk about identity through their praxis, the concept of the voice is clearly of central importance. This is a complex issue because of the, often interchangeable, allusion to the acoustics of the voice (how the sound of the voice defines the self), and the ideological questions around who has a voice, who gets to speak and which voices are listened to. When producing podcasts in which you are also a host, one of the principle elements that you become attuned to is the sound and affectation of your own voice, its idiosyncrasies, and the inaccuracies of your own speech. Certainly, misgivings about my own voice have entered significantly into how my perception of self and, in turn, how I wanted to present myself through the podcast (Llinares, May 11, 2016). For female podcasters, the politics of the voice is urgent as it links to a potential for podcasting to circumvent the gender hierarchies of the mainstream media. But this is much easier said than done. Indeed, a discourse around the gendered voice, conceptions of authority, and the phenomena of vocal fry as an affectation of younger female voices, have accompanied the podcasting's more recent mainstream visibility. (Miller 2015; Fresh Air 2015; Wolf 2015; Tiffe and Hoffmann 2017) Interestingly, Christine Mottram acknowledges that the gendering of vocal authority suggests that traditionally lowerpitched voice is associated with authority, yet argues that podcasting represents a 'shift in audience and speaker dynamics' in which 'finding vocal authority in podcasts is not about achieving the traditional Western aesthetic of the low, deep voice, but about sounding like a "real" person: individually authentic'. (2017: 66)

Conveying through the voice a sense of individual authenticity rather than an omnipotent authority arguably correlates with the egalitarian ideal of the internet age. The resonance of a passionately authentic voice, rather than a more objectively dispassionate delivery, could reflect a cultural shift away from the paternalism of traditional structures of the public sphere and the reliance on expert (usually white, male) voices. Pointedly, for the academics I have talked to (myself included), 
the decoupling of knowledge from a highly formalised, austere, even deliberately dull forms of delivery, is a central advantage to podcasting related to the creative use of sound to articulate knowledge. Rachel Leventhal-Weiner argues that podcasting has been the mechanism through which she has found her voice:

\begin{abstract}
In podcasting, I have found a definitive voice and viewpoint, something I have always struggled with in writing and in advocacy. I learned to be more forceful with the case I was making, with the evidence I provide, with the drama I use to convey my ideas. I have learned to be less measured and more passionate. Podcasting is a special medium-you can't rely on body language or facial expressions to reach an audience. It's just you, the microphone, and your voice. (March 31, 2017)
\end{abstract}

Leventhal-Weiner alludes here to an interconnection between ideological paradigms of having a voice, and the important of aesthetic use of that voice in evoking what one wants to get across. This notion has a philosophical ancestry in Barthes notion of 'Grain of the Voice' (1977), but perhaps even more pertinent alignment is with Karpf (2007) research on the gendered voice and more recently Rodero's analysis of prosodic features of speech and the impact on perception of audio content (2015). But what, one might ask, is the difference between podcasting and other mediums in suggesting form has an impact on the perception of content, or that there are ideological hierarchies that afford the dominance certain identities and groups. Podcasting obviously puts a premium of voice as the central tool of expression and communication. Furthermore, the liminal infrastructure of production, distribution and exhibition instils a sense of independence and autonomy, and within a new listening context in which the sense of interest and connection underpins the choice to listen, independent podcasting fosters a move away from authorial, top down dissemination of information to a more conversational, personal and subjective tone. The persona, experience, sound of the voice, feed intrinsically into the words spoken, thoughts expressed, which again points to a praxis of the active materialization of ideas through podcasting in which the effects and understanding of mediation are learnt through the experience of mediated subjectivity.

\title{
Conclusion
}

In writing this chapter I have been acutely aware of the irony of setting down assertions about the idealized possibilities of podcasting praxis in written form. If you lend any credence to argument around sound versus writing, the mediation of identity, potential effects on how we understand the communication of knowledge, there is a fundamental epistemological flaw gnawing at very purpose of this book. What has emerged in the writing of this chapter, and my continued work in the medium of podcasting, are further questions with regard to its application and a host of potential further avenues for enquiry. On an instrumental and philosophical level, podcasting offers the potential for new avenues of enquiry regarding interrelationship between sound and writing. In the context of higher education, podcasting's wider as a primary method of research dissemination could be a fundamental strand of the open access movement challenging the problems of the academic publishing industry and, in the process, providing a way of bringing research out of the ivory tower. Podcasting can even be deployed as a research method in and of itself, as an archive of primary audio data, its praxis helping to challenge disciplinary silos, within and across academia and, as the last section of this 
chapter points towards, fostering the communication of research in modes where the identity and persona of the researcher is not exorcised in name of objectivity, but understood as key parameters in the communication of knowledge.

There are fundamental caveats to the assertions and arguments I have explored. My own experiences have influenced a positive understanding of the applications of the medium both in terms of its individual effects but also in terms of wider media culture. A sense of what podcasting offers through its liminal praxis, and the dynamics in challenging disciplinary and communicative boundaries in a way that offers a freedom and autonomy, has the potential to be explored, and challenged, much further. However, in a media age which often seems completely chaotic and arbitrary, and governed by immediate, ephemeral and often superficial communication modes that fermenting amplified individualization and polarization, the very liminality of podcasting - its flexibility, transcendence of boundaries between media which may be conceived as 'old' and 'new' and across practices of production, distribution and consumption - offers a coherent space where thought, identity and practice find common purpose.

\section{Bibliography}

Augoyard, J-F. and Torgue, H. (2005) Sonic experience: a guide to the effects of sound. Montréal: McGill-Queen's University Press.

Barthes, R. (1977) Image Music Text. London: Fontana Press.

Berry, R. (2006) 'Will the iPod kill the Radio star? Profiling Podcasting as Radio', Convergence, 12 (2): 143-162.

Berry, R. (2015) 'A Golden Age of Podcasting: Evaluating Serial in the Context of Podcast Histories', The Journal of Radio and Audio Media, 22 (2): 170-178.

Bottomley, AJ. (2015) 'A decade in the life of a "New" audio medium: Introduction', Journal of Radio and Audio Media, 22 (2): 164-169.

Brodbeck, D. (2017) [Interview] April 27, 2017.

Cowley, N. (2008) 'What is Praxis? Discussed in relation to Hegel, Marx, Nietzsche and Sartre', TKKA: Graduate and PostGraduate E-Journal, Vol 4. [Internet] Accessed 1 Nov 2017.

de Certeau, M. (1988) The Practice of Everyday Life. Berkeley, Calif.; London: University of California Press.

Dann, L. (2017) [Interview] May 5, 2017.

Dann, L. (2017-) Blood Culture, www.blood-culture.com, [Podcast] Accessed September 4, 2017.

Dean, M. (2017) 'Voices of America: can podcasts tell more than stories of individual expression?', www.newrepublic.com, [Internet] Accessed 25 May, 2017.

Derrida, J. (1976) Of Grammatology, trans. Gayatri Chakravorty Spivak. Baltimore: The Johns Hopkins University Press. 
Donnelly, K. M. and Berge, Z.L. (2006) 'Podcasting: co-opting MP3 players for education and training purposes', Online Journal of Distance Learning Administration, 9 (3), [Internet] Accessed on 11 May 2017.

Dunham, L. (2016-) 'Woman of the Hour', www.art19.com, [Podcast] Accessed September 26, 2017.

Edmonds, D. and Warburton, N. (2012) Philosophy Bites. Oxford: University Press.

Freire, P. (1970) Pedagogy of the Oppressed. London: Continuum.

Fritz, J.H. (2015) Plato and the Elements of Dialogue. Lexington Books.

Gabrielsson, A. (2001) ‘Emotion perceived and emotion felt: Same or different?', Musicae Scientiae, 5(1): 123-147.

Ganesh, J. (2016) 'Podcasts create golden age of audio', www.ft.com [Internet] Accessed 19 May, 2017

Gladwell, M. (2016-) 'Revisionist History', www.revisionisthistory.com, [Podcast] Accessed June 2, 2017.

Gross, T. (2015) 'From Upspeak to Vocal Fry: Are We 'Policing' Young Women's Voices', Fresh Air podcast, https://www.npr.org/programs/fresh-air/, [podcast] Access September 5, 2017.

Heise, H. (2017) 'On the Shoulders of Giants: How Audio Podcasters Adopt, Transform and Reinvent Radio Storytelling', MOOC Transnation Radio Stories. [Internet] Accessed 26 April 2017.

Herrman, J. (2016) 'Podcasts Surge, but Producers fear Apple isn't listening', www.nytimes.com [Internet] Accessed on 11 May 2017.

Hills, M. (2011) 'Participatory Culture: Mobility, Interactivity and Identity', in Creeber, G. \& Martin, R. (eds) Digital Cultures: Understanding New Media. Maidenhead: Open University Press: 117-121.

Kight, C. (2017) [Interview]. May 4.

Klein, E. (2017) 'Tim Ferris on Suffering, Psychedelics and Spirituality', www.vox.com [Podcast] accessed June 11, 2017.

Klein, E. (2016) 'Malcolm Gladwell on the danger of joining consensus culture', www.vox.com [Podcast] accessed June 8, 2017.

Leventhal-Weiner, R. (2017) Podcasting, www.roguecheerios.com, [Internet] Accessed on 12 May 2017

Leventhal-Weiner, R. (2017) [Interview] May 5, 2017.

Leventhal-Weiner, R and Dix, M. 'Boy v Girl: A Podcast'. http://boyvgirlpodcast.libsyn.com, [Podcast] Accessed, June 14, 2017.

Llinares, D. and Fox, N. (2015-) 'The Cinematologists Podcast', www.cinematologists.com. [Podcast] Accessed, March 25, 2017. 
Llinares, D. (2016) 'The Anxiety of the Speech Act-Podcast Editing and the Shaping of Meaning'. www.dariollinares.com, [Internet] Accessed 2 May, 2017

Llinares, D. and Fox, N. (2018) 'Knowing Sounds: Podcasting as Academic Practice', Journal of Media Practice, 9(1): 50-53.

Longform Podcast (2016) 'Malcolm Gladwell', www.longform.com, [Podcast] Accessed June 10, 2017

Longform Podcast (2015) 'Lena Dunham', www.longform.com, [Podcast] Accessed September 6, 2017

Madsen, V. and Potts, J. (2010) 'Voice-Cast: The Distribution of the Voice via Podcasting' in Neumark, N. Gibson, R. and van Leeuwen, T. (Eds) Vø1ce: Vocal Aesthetics in Digital Media. Cambridge, Mass: MIT Press: 33-59.

Markman, K. M. (2012) 'Doing radio, making friends, and having fun: Exploring the motivations of independent audio podcasters', New Media \& Society, 14(2): 547-565.

Markman, K. and Sawyer, C.E. (2014) 'Why Pod? Further Explorations of the Motivations for Independent Podcasting', Journal of Radio \& Audio Media, 21(1): 20-35.

McElearney, G. and Middleton, A. (2013) 'Podcasting and RSS - the changing relationship', in Middleton, E. (ed) Digital Voices - a collaborative exploration of the recorded voice in postcompulsory education, Media-Enhanced Learning Special Interest Group and Sheffield Hallam University: 18-17. [Internet] Accessed 2 May, 2017.

Meng, P. (2005) 'Podcasting and vodcasting: definitions, discussions and implications', $A$ White Paper by IAT Services at University of Missouri. [Internet] Accessed 11 May, 2017

Meyer, L.B. (2008) Emotion and Meaning in Music. Chicago: University of Chicago press.

Middleton, A. (2013) 'Digital Voices-a collaborative exploration of the recorded voice in postcompulsory education'. Media-Enhanced Learning Special Interest Group and Sheffield Hallam University, 28-32.

Millette, M. (2011) 'Independent Podcasting as a Specific Online Participative Subculture: A Case Study of Montreal's Podcasters', IR12 Association of Internet Researchers. Conference proceedings [Internet] Accessed June 10, 2017.

Miller, K. (19 May 2015) 'Why do these women's voices bother you so much?' Refinary290. [Internet] Accessed May 12, 2017.

Morris, J.W. and Patterson, E. (2015) 'Podcasting and its Apps: Software, Sound, and the Interfaces of Digital Audio', Journal of Radio \& Audio Media, 22(2): 220-230.

Mottram, C. (2016) 'Finding a pitch that resonates: an examination of gender and vocal authority in podcast', Voice and Speech Review, 10(1): 53-69.

Munro, E. (2013) 'Feminism: A Fourth Wave?', Political Insight, 4(2): 22-25.

Ong. W, (2002) Orality and Literacy: The Technologising of the word. Suffolk: Routledge.

Pierce, D. (2014) The New Radio Stars: Welcome to the Podcast Age, www.theverge.com [Internet] Accessed 14 May, 2017

Proops, G. (2013-) The Smartest Man in the World Podcast, www.gregproops.com [Podcast] Accessed, 17, April, 2017. 
Proops, G. (2015) The Smartest Book in the World, New York: Touchstone

Rodero, E. (2015) 'The Principle of Distinctive and Contrastive Coherence of Prosody in Radio News: An Analysis of Perception and Recognition', Journal of Nonverbal Behaviour, 39: 79-92.

Tiffe, R. \& Hoffmann, M. (2017) 'Taking up sonic space: feminized vocality and podcasting as resistance', Feminist Media Studies, (17)1: 115-118.

Webster, J.G. (2014) The Marketplace of Attention: How Audiences Take Shape in a Digital Age. Massachusetts: MIT press.

Williams, S. (1998) 'Modernity and the emotions: corporeal reflections on the (ir)rational', Sociology, 32(1) 747-769.

Williams, S. (2017) 'Tough Girl Podcast', www.toughgirlchallenges.com, [Podcast] Accessed April 25, 2017.

Williams, S. (2017) [Interview] May 5, 2017.

Wolf, N. (2015) 'Young women, give up the vocal fry and reclaim your strong female voice', www.guardian.co.uk [Internet] Accessed June 14, 2017. 